\title{
Modern Use of Water Produced by Purification of Municipal Wastewater: A Case Study
}

\author{
Giorgia Tomassi ${ }^{1, *}$, Pietro Romano ${ }^{2}$ and Gabriele Di Giacomo ${ }^{2, *}$ \\ 1 Department of Industrial Engineering, University of Padova, Via Gradenigo 6/a, 35131 Padova, Italy \\ 2 Department of Industrial and Information Engineering and of Economics, Campus of Roio, University of \\ L'Aquila, 67100 L'Aquila, Italy; pietro.romano@graduate.univaq.it \\ * Correspondence: giorgia.tomassi@studenti.unipd.it (G.T.); gabriele.digiacomo@univaq.it (G.D.G.); \\ Tel.: +39-3381595634 (G.D.G.)
}

check for updates

Citation: Tomassi, G.; Romano, P.; Di Giacomo, G. Modern Use of Water Produced by Purification of Municipal Wastewater: A Case Study. Energies 2021, 14, 7610. https:/ / / doi.org10.3390/en14227610

Academic Editor: José Carlos Magalhães Pires

Received: 12 October 2021

Accepted: 11 November 2021

Published: 14 November 2021

Publisher's Note: MDPI stays neutral with regard to jurisdictional claims in published maps and institutional affiliations.

Copyright: (c) 2021 by the authors. Licensee MDPI, Basel, Switzerland. This article is an open access article distributed under the terms and conditions of the Creative Commons Attribution (CC BY) license (https:// creativecommons.org/licenses/by/ $4.0 /)$.

\begin{abstract}
All the urban areas of developed countries have hydric distribution grids and sewage systems for collecting municipal wastewater to treatment plants. In this way, the municipal wastewater is purified from human excreta and other minor contaminants while producing excess sludges and purified water. In arid and semi-arid areas of the world, the purified water can be used, before discharging, to enhance the energy efficiency of seawater desalination and solve the problems of marine pollution created by desalination plants. Over the past half-century, seawater desalination has gradually met demand in urbanized, oil-rich, arid areas. At the same time, technological evolution has made it possible to significantly increase the energy efficiency of the plants and reduce the unit cost of the produced water. However, for some years, these trends have flattened out. The purified water passes through the hybridized desalination plant and produces renewable osmotic energy before the final discharge in the sea to restart the descent behaviour. Current technological development of reverse osmosis (RO), pressure retarded osmosis (PRO) and very efficient energy recovery devices (ERDs) allows this. Furthermore, it is reasonable to predict that, in the short-medium term, a new generation of membranes specifically designed for improving the performance of the pressure retarded osmosis will be available. In such circumstances, the presently estimated $13-20 \%$ decrease of the specific energy consumption will improve up to more than $30 \%$. With the hybrid plant, the salinity of the final discharged brine is like that of seawater, while the adverse effect of GHG emission will be significantly mitigated.
\end{abstract}

Keywords: freshwater from the sea; purification of municipal wastewater; osmotic energy; reverse osmosis; pressure retarded osmosis; process integration; energy efficiency; environmental sustainability

\section{Introduction}

The total volume of water on Earth is estimated at 1.386 billion $\mathrm{km}^{3}$, with $97.5 \%$ being saltwater, having an average concentration of $35 \mathrm{~g} / \mathrm{L}$. The remaining water is freshwater, of which only $0.3 \%$ is in liquid form on the surface [1].

Freshwater availability is naturally produced by evaporation from the oceans and subsequent recondensation and precipitation, as was already observed by Aristotle [2,3] Unfortunately, it is unevenly distributed on the planet and rarely meets the requirements for many uses by humans and animals.

In developed countries, the per-capita human consumption of freshwater is about $200 \mathrm{~L} / \mathrm{d}$, sometimes even double. Both agricultural and industrial activities also require a large amount of freshwater [4]. To overcome freshwater scarcity, oil-rich countries started to build and operate evaporative desalination plants like multi-stage flash (MSF), multipleeffect distillation (MED), and multi-effect thermal vapor compression desalination (TVC). Shortly, the production of freshwater from the sea became popular in other developed countries. Furthermore, the use of semipermeable membranes to reject dissolved salts was 
demonstrated to be a better way for seawater desalination [5]. In 2018, the global share of the RO for seawater desalination was about $65 \%$, with an increasing trend [6].

The history of industrial desalination dates to the beginning of 1950, with the birth of the Office of Saline Water (OSW) in the United States of America, which gave the first strong impulse to develop efficient technologies for industrial production of freshwater from the sea. In 1963, all the installed capacity of desalination plants was about a thousand $\mathrm{m}^{3} / \mathrm{d}$ of freshwater [2]. In 1975, the first automatically controlled MSF desalination plant, with a production of two thousand $\mathrm{m}^{3} / \mathrm{h}$ of freshwater (the largest in the world at that time), was built and put into operation in Italy (with Italian technology), serving the water needs of the Porto Torres industrial site in Sardinia $[7,8]$. Subsequently, numerous other plants were built worldwide, particularly in the emirates bordering the Persian Gulf. According to the latest inventory (30th Desal Data) published in October 2017 by the International Desalination Association (IDA) together with Global Water Intelligence (GWI), the global production of freshwater from the sea was 92.5 billion L/d with 19,372 plants located in 150 countries, against 88.6 billion L/d e and 18,983 plants of the previous year. It is worth noting that ten years earlier, the production of desalted water was about half. This strong growth, associated with the introduction of modern and cheaper technologies, resulted in a significant decrease in the unit cost of freshwater and an equally considerable increase in the energy efficiency of desalination plants. In recent years, the produced water unit cost $\left(0.53\right.$ to $1.2 \mathrm{US} \$ / \mathrm{m}^{3}$ ) and energy efficiency ( 2 to $3 \mathrm{kWh} / \mathrm{m}^{3}$ of freshwater) have reached stable values $[2,9,10]$.

On the other hand, environmental problems related to the discharge of very concentrated brines and global warming of the planet have arisen [11,12].

It remains that water security is one of the principal global risks, particularly in developing and underdeveloped countries that have a tremendous and urgent need for large quantities of freshwater produced at sustainable cost and low environmental impact. About a third of the world's population already lives in countries considered to be in water emergencies. If this trend continues, two-thirds of the earth's population will be thirsty in twenty years [2,13]. For this, the international exposition held in Milan in 2015, "EXPO Milano 2015," organized and hosted the "Water Forum," aiming to make public and private entities aware of this serious issue and stimulate the adaption of the legislation and new investments capable of tackling the problem adequately [14]. The availability and sustainable management of water were also featured prominently in the 6th Sustainable Developments Goals (SDGs) of the 2030 Agenda for Sustainable Development, agreed to by 193 nations in 2015 [15]. Undoubtedly, desalination is essential to bridge the water supply gap expected in the increasingly water-demanding world. The research and development activity to re-establish the growth of seawater desalination at a sustained pace is very intense. To this purpose, it is necessary to change the paradigm that brine and water contaminated by organic compounds are not wastes but sources for additional freshwater, energy, and useful materials. This may be realized, in the short-medium term, by accomplishing seawater desalination using processes obtained through the integration of two or more technologies already consolidated, and through the integration of two or more already existing systems. An example is the one described in an old article concerning the recovery of Magnesium from the brine of an MSF plant [16]. As highlighted in the article, with the hybrid process, Magnesium is produced from a solution that has a concentration approximately double that of seawater. Furthermore, this solution does not require any pre-treatment as it is the product of pre-treated seawater. The advantages of sustainability and environmental impact are equally evident as the ocean represents an inexhaustible and renewable source of Magnesium while mineral resources are limited. The same goes for other metals of increasing commercial importance, such as lithium [17]. The status and prospects of hybrid processes using brine, thermal waste, and water from wastewater purification are described in detail in several recent publications [18-22]. These processes aim to increase the productivity and energy efficiency of desalination, reducing the environmental impact. To this purpose, it is worth citing the ongoing research and 
technological development activities for improving the performance of the membranes through the homogenization of the density of the filtering surface, as well as the reduction of the bilateral polarization effects by modification of their hydrophobicity at the nanoscale. It seems reasonable to predict that such membranes could be available for full-scale application in the short-medium term [23]. When applied to seawater desalination, a different but not ready applicable way is to use new separation technologies characterized by better performance and economic feasibility [20,23-31].

Everyone agrees that process integration is the primary way to increase productivity, diversify the use of raw materials and products, and reduce the cost of desalination in the context of general sustainability. At the same time, the relentless substantial increase of RO desalination plants' market share is a fact. We did not find any evidence on the construction of new plants of the classic evaporative (MSF), multiple effects distillation (MED), or thermocompression (VTC) types. Of these, the RO-PRO is the one that appears most interesting both in terms of feasibility on an industrial scale and for future prospects [22,30,32-36]. This integration can be achieved with different schemes and with different types of impaired, low salinity water. These options have been analysed using theoretical models to find the best way of combining RO with PRO [32]. However, the conclusion led to conflicting results as a consequence of the many assumptions required by the models. As supported by others [37], we believe that combining the impaired, low salted water with the most concentrated brine is the best configuration for the RO-PRO hybridization.

In arid, urban places, the freshwater produced by seawater desalination is first distributed and used, collected through the sewage grid, purified in the wastewater treatment plants (WWTPs), and finally discharged into the sea at the net of losses. Therefore, there are two comparable streams, i.e., one of desalted water (PW) and one of very concentrated brine. These two streams can meet in the PRO section of the hybrid RO-PRO plant to directly transfer the resulting osmotic power to a portion of the incoming pre-treated seawater (PSW). RO-PRO integration can be achieved in several ways, just as the renewable energy produced within the hybrid plant can be transferred to PSW, with different equipment $[18,38,39]$. The results that can be obtained are different and depend on the specific conditions in which the desalination plant operates. Regarding the location, there is a vast choice, since, in the world, there are many urban areas where a new seawater desalination plant exists or is necessary. The most critical and, at the same time, most favourable situation is that of the urban areas of the Persian Gulf where there is the highest concentration of desalination plants, both of the evaporative and of the RO type. The criticality depends on the fact that seawater salinity is significantly higher than the average. The advantage derives from a wider choice, from the simultaneous presence of plants based on different technologies and old plants. The results of the research in those conditions of salinity and aridity are undoubtedly conservative. Therefore, once a well-defined configuration for the hybrid RO-PRO desalination processes was selected, this research aimed to describe and evaluate its performance in an arid urban area of the Persian Gulf. More specifically, we aimed to quantify the amount of renewable osmotic energy produced inside the hybrid desalination plant, integrating already available services and technologies. Then, we wanted to quantify the difference between the hybrid process's specific energy consumption (SEC) by comparison with a modern RO stand-alone desalination process, along with other beneficial effects. Furthermore, we aimed to quantitatively show how the energy efficiency of desalination improves, increasing the operating pressure of the PRO section.

\section{Materials, Methods, Processes and Products}

The salinity (TDS) of the seawater was assumed to be $43 \mathrm{~g} / \mathrm{L}$, following the assumption that the desalination plant is in an arid and urban area of the United Arab Emirates (UAE) in the Persian Gulf [39]. This choice is because there is the highest density of desalination plants (equal to $48 \%$ of the world total $[40,41]$ ), and it is one of the world's driest places exposed to a chronic freshwater shortage [42]. 
It is further assumed that the desalting plant is of the RO stand-alone type, having a recovery factor of $40 \%$ and an operating pressure of 70 bar. The plant is equipped with Pressure Exchangers (PXs) as energy recovery devices with 95\% efficiency. Inside the PX, a balanced flow is maintained (i.e., high and low-pressure flow rates are equal) to maximize pressure exchange [43,44]. The TDS of the brine is about $7.2 \%$, while its pressure is 70 bar. Freshwater is produced at atmospheric pressure with a TDS lower than $0.02 \%$. The operating temperature is $30^{\circ} \mathrm{C}$.

Apart from freshwater and very diluted salted solution, the osmotic pressure $(\pi)$ of the seawater and brine cannot be quantitatively calculated by the classical van't Hoff equation due to the significant deviation from the ideal behaviour resulting from the high concentration of the salt. As shown in previous work [45], the following non-simplified van't Hoff equation can satisfactorily account for this phenomenon up to very high values of TDS, as well as for the operating temperature (T).

$$
\pi=\frac{-R T \cdot \ln \left(a_{w}\right)}{\bar{V}_{w}}
$$

Here $a_{w}$ represents the activity of the water and $\overline{V_{w}}$ represents the partial molar volume of the water in the seawater solution (SW), which could be approximated with the molar volume of the pure water, $V_{w}(\mathrm{~L} / \mathrm{mol})$ at the current $T(\mathrm{~K})$. When the value of the universal gas constant $R$ is equal to $0.0831446261815324, \pi$ results in bar [46].

Alternatively, Figure 1, obtained by fitting experimental data available in the literature $[47,48]$ can be confidently used at $30^{\circ} \mathrm{C}$.

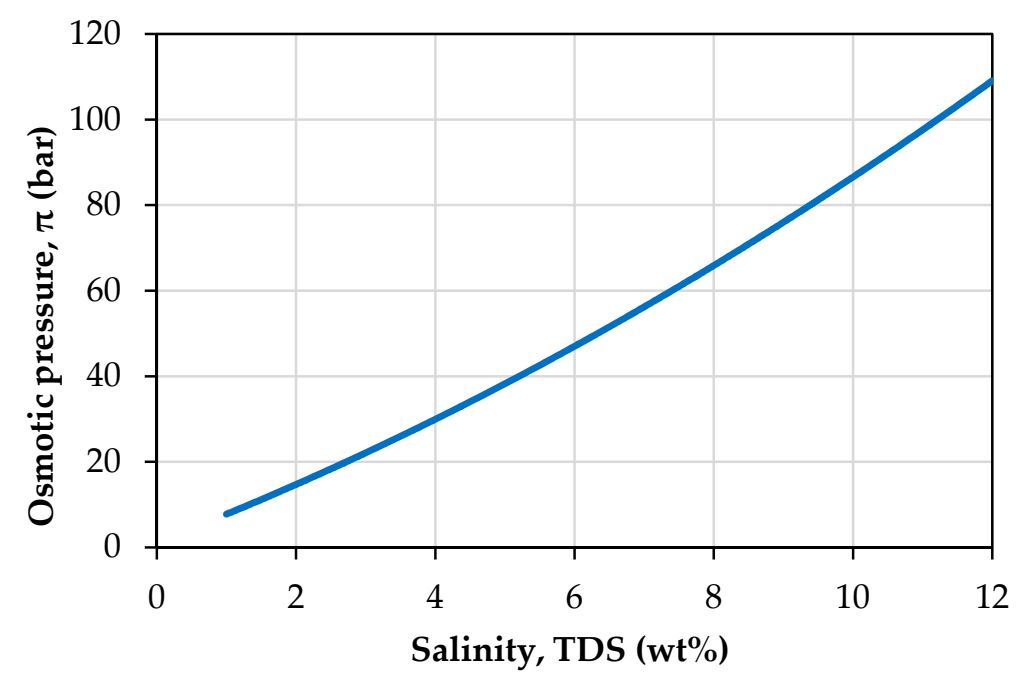

Figure 1. Osmotic pressure of seawater and its diluted and concentrated solutions as a function of the TDS at $30^{\circ} \mathrm{C}$.

Considering the flow rate $\mathrm{PW}$ entering the PRO section, it is assumed to be equal to $85 \%$ of the freshwater (FW) produced by the RO of seawater, accounting for evaporation and possible leaking in the hydric distribution grid, and in the sewage system. It comes from the activated sludge or similar (WWTPs) serving the urban area. To justify this assumption, it is worth considering that this technology is by far the most diffused and consolidated, with an efficiency higher than $99 \%$. It is also worth emphasizing that when evaporative desalting plants co-exist in the same area with RO based plants, the unsalted stream can be even much higher. Furthermore, it is assumed that the TDS of PW is equal to zero, the operating pressure of $\mathrm{PRO}$ is in the range 22-31 bar, and both purified water and brine at atmospheric pressure do not need any pre-treatment before entering the PRO plant. In addition, high-pressure and booster pumps efficiencies were considered equal to $85 \%$ and $75 \%$, respectively [44]. 
Finally, the (SEC) as $\mathrm{kWh} / \mathrm{m}^{3}$ of freshwater produced by the hybrid RO-PRO desalination process was calculated with the following equation [38].

$$
S E C=\frac{P_{p u m p s}^{T O T}}{Q_{F W}}
$$

where $Q_{F W}\left(\mathrm{~m}^{3} / \mathrm{h}\right)$ is the constant flow rate of the freshwater produced by the RO section and $P_{\text {pumps }}^{T O T}(\mathrm{~kW})$ is the sum of the power required by each pump.

Figure 2 schematically shows a typical activated sludge WWTP widely used to purify municipal wastewater mainly contaminated by human excreta. As can be seen, there are two effluent streams: very wet sewage sludge (SS) and purified water (PW), which is usually discharged into some superficial water body or directly into the sea. Several books, scientific papers, and reviews were published and are ongoing on the final disposal of SS [37,48-56], but much less attention was addressed to better use of PW.

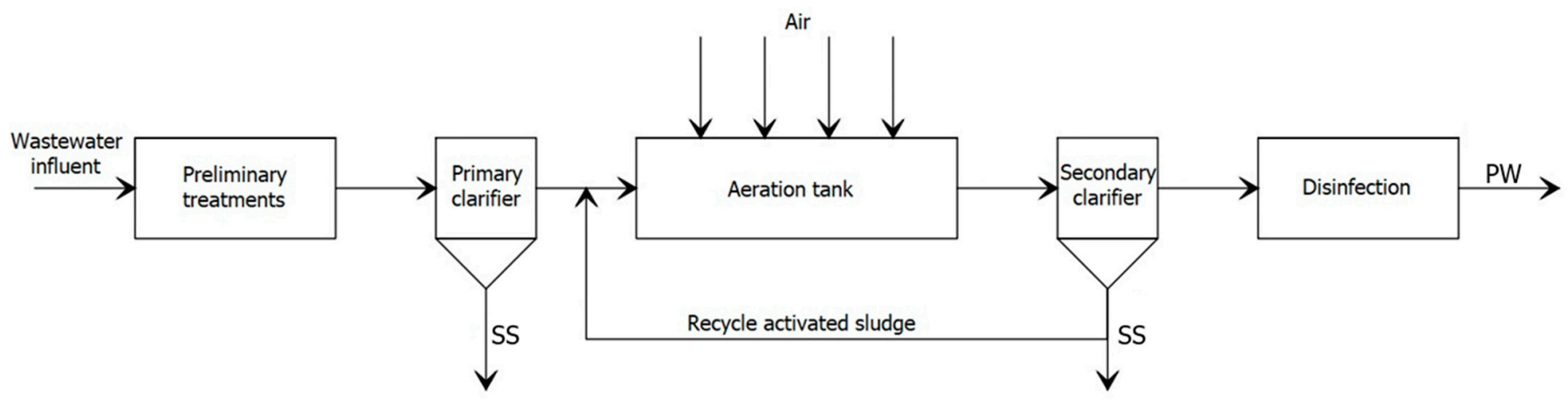

Figure 2. Schematic diagram of a typical activated sludge WWTP.

Figure 3 schematically shows a Traditional Seawater Reverse Osmosis (TSWRO) process.

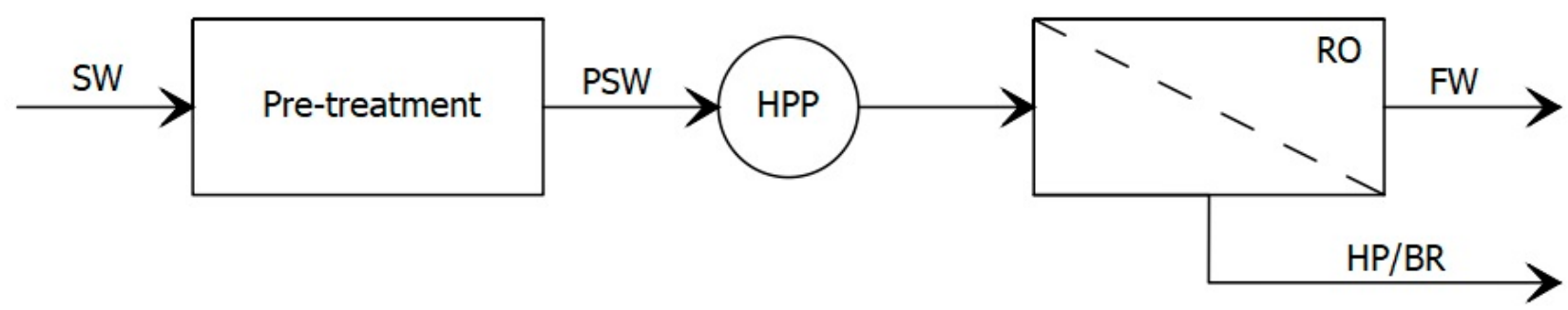

Figure 3. Schematic diagram of a traditional RO seawater desalination process TSWRO.

The pre-treatment unit removes particles and suspended solids in the feed stream that may cause fouling and scaling on the RO membrane surface. The high-pressure pump (HPP) raises the feed pressure from atmospheric to a value adequately higher than the osmotic pressure of the final brine. Then, PSW enters the RO system, where FW flows through the semipermeable membranes while the salts are almost entirely rejected. The Permeate FW is taken as a product after minor treatment at atmospheric pressure, while the pressurized retentate or brine, $\mathrm{HP} / \mathrm{BR}$, is a waste characterized by high salt concentration $\left(\mathrm{TDS}_{\text {brine }}>>\mathrm{TDS}_{\text {seawater }}\right)$. TSWRO initially operated at the lowest possible pressure to avoid membrane modules' mechanical stress and minimize the energy for feed pressurization. The recovery, operating in this condition, was low, and the TDS of brine was not significantly different from the TDS of PSW. With better performing membranes and new sophisticated Energy Recovery Devices (ERDs), the modern RO desalination plants adopted more convenient operating conditions to reduce the value of the SEC [57].

In fact, the value of the SEC, and related operating cost, for RO desalination is mainly determined by the energy required for PSW pressurization [13]. Investment and operat- 
ing costs, as well as other energy-consuming operations (e.g., pre and post-treatments, construction, maintenance), are not susceptible to further improvements, as they are definitively optimized together with the potential of the plants. For this, the new RO based SW desalination plants are equipped with a section for recovering most of the energy of the pressurized brine.

Figure 4 schematically shows an improved seawater desalination process by Reverse Osmosis (ISWRO). As can be seen, an isobaric Pressure Exchanger (PX) pressurizes a portion of PSW by using the HP/BR stream. The rate of $\mathrm{PSW}_{2}$ is the same as that of the brine to maximize the performance of PX. Then, the low-pressure brine (LP/BR) is discharged, whereas the pressurized $\mathrm{PSW}_{2}$ is added by a booster pump (BP) to $\mathrm{PSW}_{1}$ and enters the RO modules. Pressure exchangers were introduced in 2001 [57], and their efficiency is over $96 \%$ [58]. The value of the SEC for an industrial desalination plant built and operated according to Figure 4 is still significantly higher than the calculated theoretical minimum for seawater desalination $\left(1.06 \mathrm{kWh} / \mathrm{m}^{3}\right)$ [57]. There is, therefore, ample room for improvement concerning energy efficiency. Furthermore, a serious environmental problem is associated with the discharge of highly concentrated brines into the sea [11].

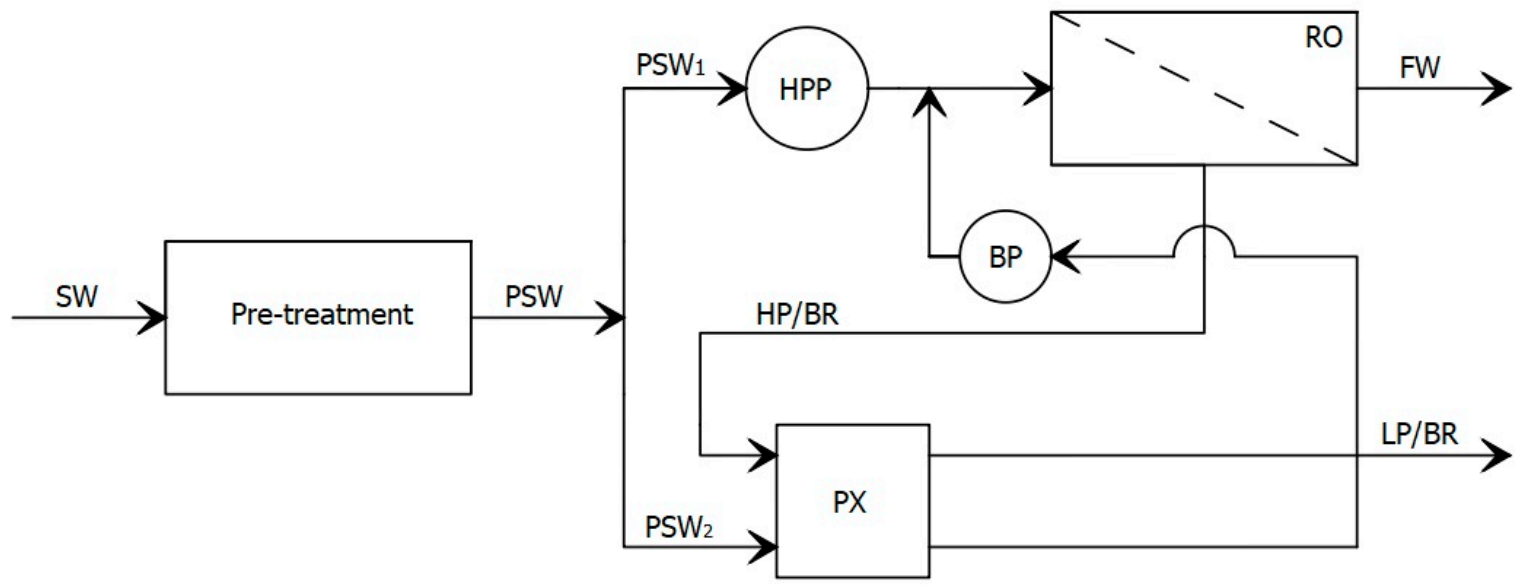

Figure 4. Schematic diagram of a typical modern RO seawater desalination process ISWRO with energy recovery from the brine.

For these reasons, it may be advantageous to consider a natural osmosis process, known as PRO, that can be carried out with the same membranes and filter modules used in $\mathrm{RO}$ based desalination plants. Figure 5 schematically shows the working principle of the PRO.

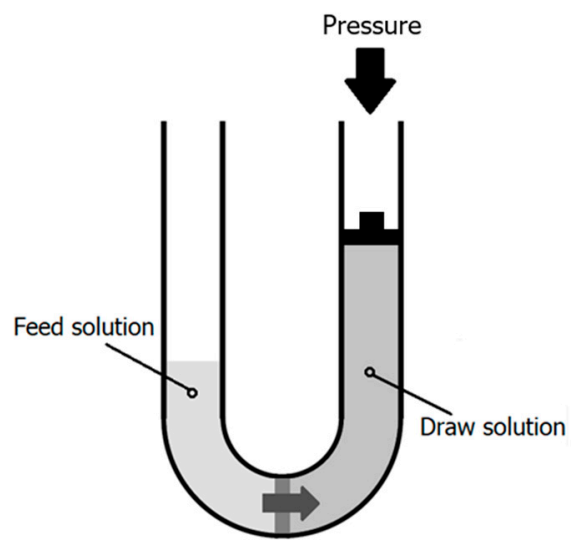

Figure 5. PRO working principle. 
As can be seen, the pressurization of a stream of salty water (draw solution) up to a value lower than its osmotic pressure [26] allows freshwater (feed solution) to flow through the semipermeable osmotic membrane to mix with the draw solution [59]. The result of this simple osmotic process is a pressurized stream of brackish water that can be used for producing renewable energy, as schematically shown in Figure $6[11,60]$.

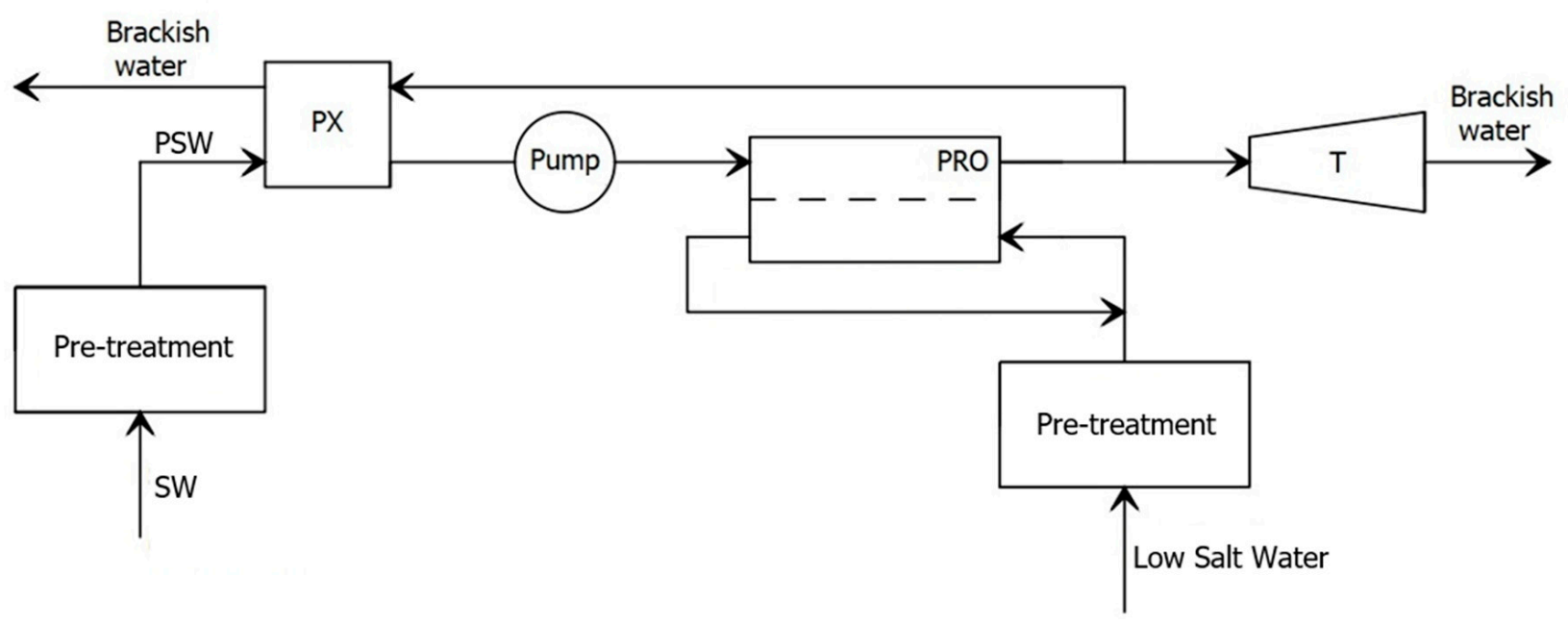

Figure 6. Schematic diagram of typical PRO process for the production of renewable osmotic energy.

The necessary condition for the operation of this technology is the presence of two currents with different salinity, such as river and seawater [61]. Although the PRO standalone process has been conceived as a technology for making renewable energy, currently, it is not economically competitive compared to other forms of renewable energy available, as stated by the Norwegian renewable energy company Statkraft [11,62].

It may be viable, using the osmotic energy produced by PRO, to directly pressurize, by a Dual Work Exchanger Energy device (DWEER), a liquid stream portion of PSW to be desalted by $\mathrm{RO}$, from the atmospheric pressure up to a pressure close to the pressurized draw solution in the PRO [11,63]. It is worth underling that, contrary to PX, the DWEER completely avoids any mixing between the pressurized and the pressuring streams, while maintaining an efficiency above $95 \%$. In such a way, the quality of the FW is the same as that produced by the ISWRO stand-alone. Figure 7 schematically shows the hybrid desalination process obtained by properly interconnecting $\mathrm{RO}$ and $\mathrm{PRO}$ along with a PX and a DWEER, and all the required pumps.

As can be seen, in this way, the $\mathrm{PSW}_{2}$ stream is partially pressurized by renewable energy before entering the $\mathrm{RO}$ section. In addition, the TDS of the discharged low pressure brackish (LP/BW) is considerably lower than the LP/BR discharged when using the process schematically depicted in Figure 4 . The draw solution feeding the PRO section is the medium-pressure brine, MP/BR, leaving PX. Considering the purified water stream, $\mathrm{PW}$, feeding the same section, it is worthy of highlighting that, in an arid urban area, it usually comes from the sewage water treatment plant, which receives all the polluted water from the urban sewage system. At least in principle, this process should be more energetically efficient than the ISWRO desalination one, and simultaneously, it should represent the solution to the environmental concerns related to the discharge of very concentrated brine. Both these effects will be quantified and critically analysed in the following section. 


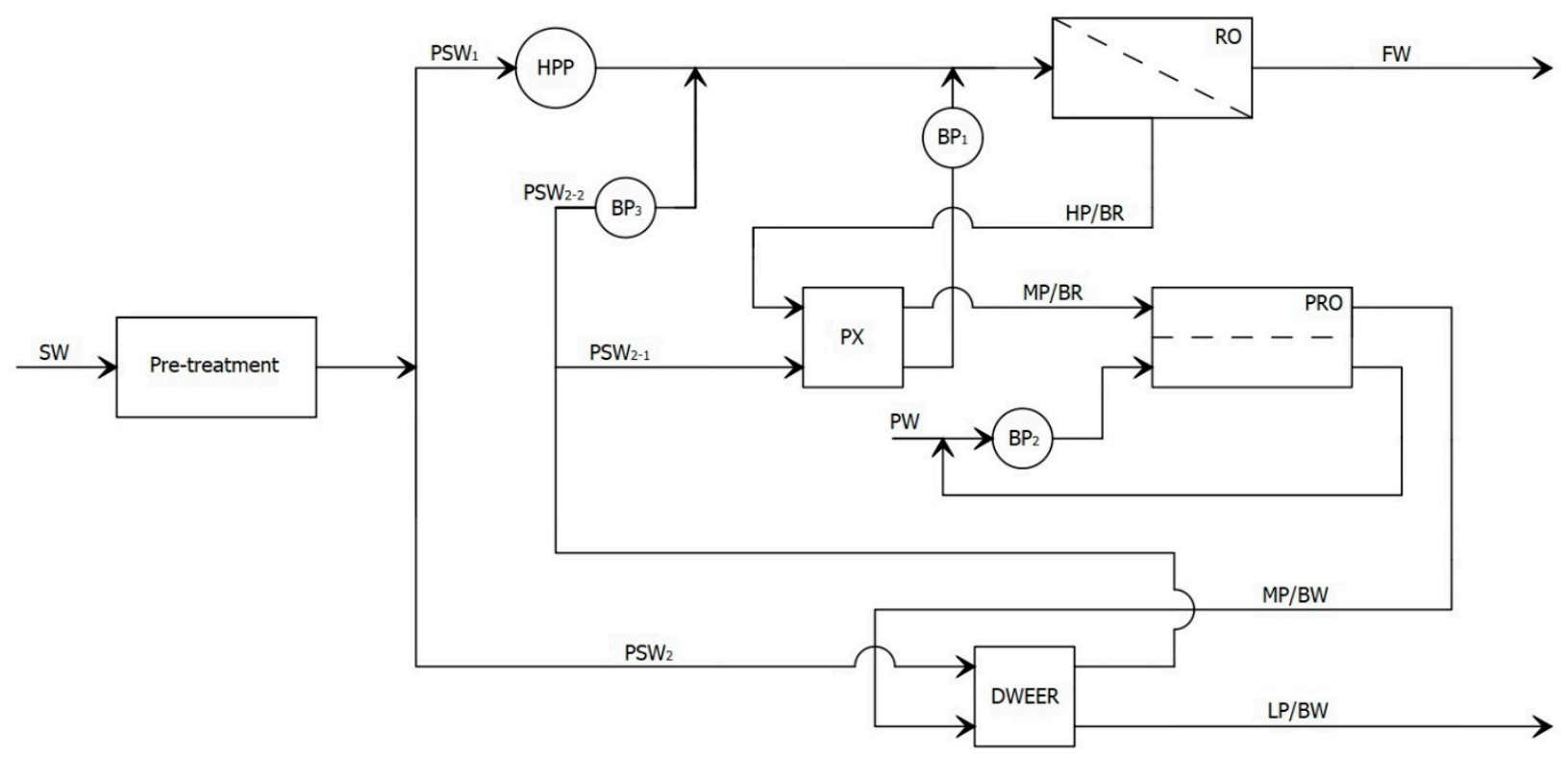

Figure 7. Schematic diagram of the selected RO-PRO hybrid desalination process for an arid urban area.

\section{Results and Discussion}

The volumetric flow rate, temperature, pressure, salinity, and osmotic pressure are reported in Tables 1 and 2; the first refers to an ISWRO process (Figure 4), while the second refers to the RO-PRO hybrid process (Figure 7). As can be seen, starting with an arbitrarily fixed flow rate of a PSW equal to $1000 \mathrm{~m}^{3} / \mathrm{h}$, and according to the assumption made in the previous section, $\mathrm{FW}$ is always equal to $400 \mathrm{~m}^{3} / \mathrm{h}$, since the recovery factor was equal to $40 \%$, in both cases. Considering the hybrid process, $\mathrm{PW}$ is $85 \%$ of $\mathrm{FW}$, or $340 \mathrm{~m}^{3} / \mathrm{h}$. It is worth emphasizing that the arbitrary assumption made for the flow rate of FW does not represent any limitation for the generality of our approach to quantify the value of the SEC and the concentration of the discharged saline solution in both cases.

Table 1. Material balances and relevant properties of the incoming and the outcoming liquid streams for the ISWRO desalination process.

\begin{tabular}{cccccc}
\hline Stream & $\begin{array}{c}\text { Volumetric } \\
\text { Flow Rate, } \mathbf{Q} \\
\left(\mathbf{m}^{3} / \mathbf{h}\right)\end{array}$ & $\mathbf{T}\left({ }^{\circ} \mathbf{C}\right)$ & $\mathbf{P}(\mathbf{b a r})$ & $\boldsymbol{\pi}(\mathbf{b a r})$ & TDS (wt $\%)$ \\
\hline $\mathrm{PSW}$ & 1000 & 30 & 1 & 32 & 4.3 \\
$\mathrm{FW}$ & 400 & 30 & 1 & - & 0.02 \\
$\mathrm{LP} / \mathrm{BR}$ & 600 & 30 & 1 & 58 & 7.2 \\
\hline
\end{tabular}

Table 2. Material balances and relevant properties of the incoming and the outcoming liquid streams for the selected RO-PRO hybrid desalination process.

\begin{tabular}{cccccc}
\hline Stream & $\begin{array}{c}\text { Volumetric } \\
\text { Flow Rate, } \mathbf{Q} \\
\left(\mathbf{m}^{3} / \mathbf{h}\right)\end{array}$ & $\mathbf{T}\left({ }^{\circ} \mathbf{C}\right)$ & $\mathbf{P}(\mathbf{b a r})$ & $\boldsymbol{\pi}$ (bar) & TDS (wt $\%)$ \\
\hline PSW & 1000 & 30 & 1 & 32 & 4.3 \\
PW & 340 & 30 & 1 & - & 0 \\
FW & 400 & 30 & 1 & - & 0.02 \\
LP $/ \mathrm{BW}$ & 940 & 30 & 1 & 35 & 4.6 \\
\hline
\end{tabular}

In addition to what was underlined earlier, it is worth emphasizing that the flow rate of the discharged stream from the hybrid RO-PRO process is higher than that of the ISWRO 
process. However, the salinity of this stream is quite different: the ISWRO process is about 1.7 times higher, while for the RO-PRO hybrid process it is only 1.07 times higher, thus solving marine pollution.

Considering the energy efficiency, the blue line in Figure 8 shows the behaviour of the SEC for the selected RO-PRO process as a function of the PRO pressure $\left(P_{P R O}\right)$, from zero up to an ideal value equal to the osmotic pressure of the LP/BR solution. As can be seen, the SEC decreases from the value associated with an ISWRO process to that of the hybrid RO-PRO process having an ideal PRO section. Quantitatively, this trend is given by the following equation:

$$
\mathrm{SEC}=9 \mathrm{E}-0.6 P_{P R O}^{3}-0.0009 P_{P R O}^{2}+0.0004 P_{P R O}+2.45
$$

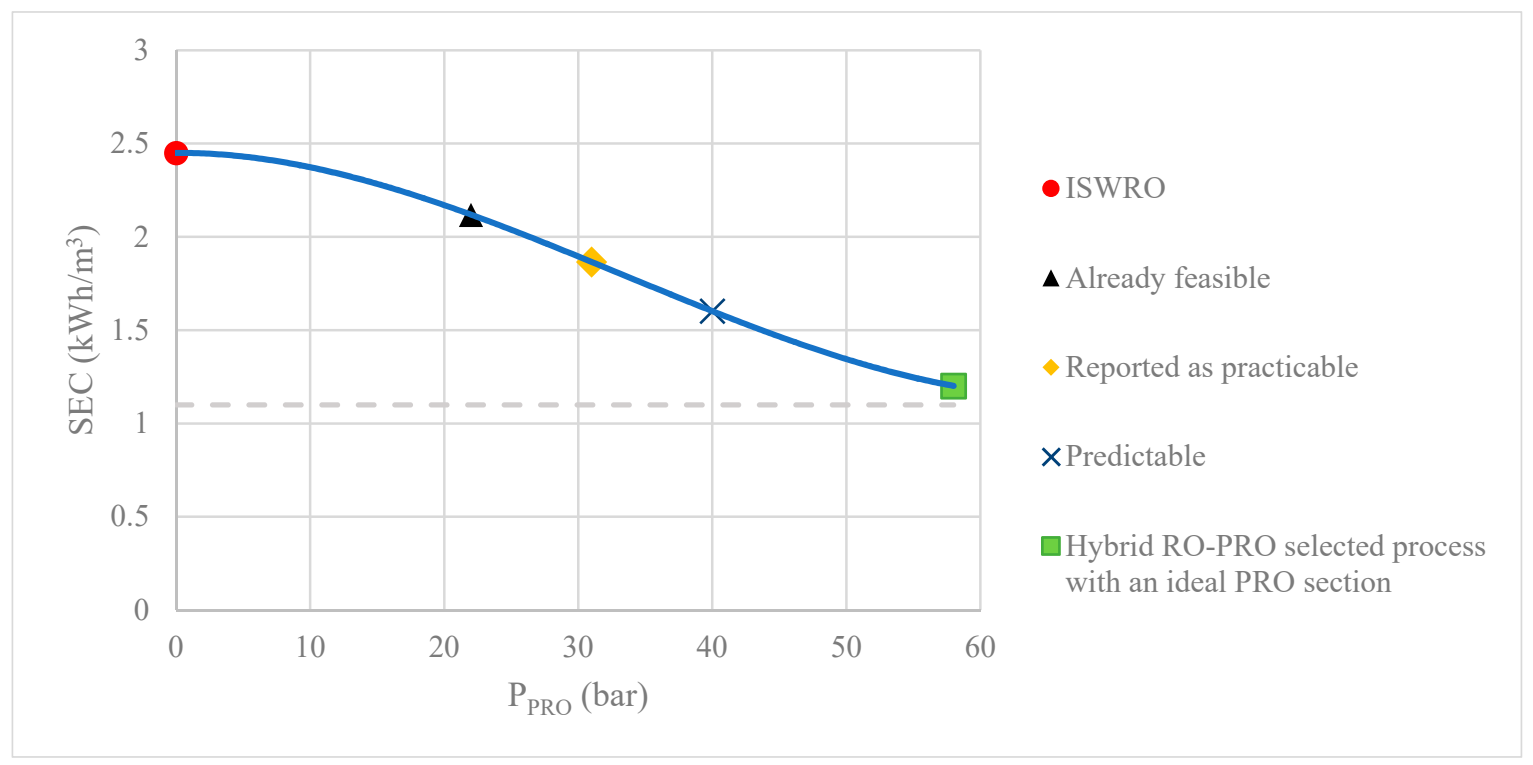

Figure 8. SEC behaviour of the selected hybrid RO-PRO desalination process as a function of the operating pressure of PRO. The dashed line represents the theoretical energy required for desalting seawater with an average TDS of $3.5 \mathrm{wt} \%$.

The SEC was calculated by Equation (2) according to the assumption made earlier on about the overall efficiency of each pump, of PX, and of DWEER. Overall:

- when $P_{P R O}=0$, there is no improvement in the energetic efficiency of the desalination. The value of the SEC would be the same as that of the ISWRO since the hybrid process would generate no indigenous osmotic power. In this condition, PRO acts as a forward osmosis section.

- If PRO could operate in the other ideal limiting condition ( $P_{P R O}$ equal to the osmotic pressure of LP/BR), the energy efficiency of desalination would increase drastically. In fact, in this case, much renewable energy would be produced inside the desalination plant in the form of osmotic pressure and be directly used for the partial pumping of seawater to the reverse osmosis plant.

- With PRO working between 22 and 31 bar (already applicable in conditions $[37,38]$ ), the value of the SEC would be in the range from $12.7 \%$ to $24 \%$ lower than that corresponding to that of ISWRO.

- With PRO working at 40 bar (foreseeably applicable at short-medium term), the value of the SEC would be about 30\% lower than that corresponding to that of ISWRO.

As a consequence of the redaction of the SEC, the GHG pollution is also mitigated since the present reduction of $\mathrm{CO}_{2}$ produced by the hybrid process is in the range of $0.2-0.45 \mathrm{~kg} / \mathrm{m}^{3}$ of FW. At the short-medium time, it is reasonably predictable as $0.6 \mathrm{~kg} / \mathrm{m}^{3}$ of FW. 


\section{Conclusions}

In arid urban areas, such as those of the Persian Gulf, seawater desalination is the only system of supplying the drinking water needed. Currently, this inevitable activity is associated with high consumption of non-renewable energy and, in many cases, with nonmarginal pollution problems linked to the discharge of excessively concentrated brines into the sea.

The results of this research highlighted the possibility of mitigating or solving these problems by the rational use of purified municipal wastewater. Instead of discharging it directly into the sea, this aqueous current, practically unsalted, can be employed to produce renewable osmotic energy inside the desalination plant. This energy is used directly, by a very efficient DWEER, to partially pressurize the seawater fed to the Reverse Osmosis for producing freshwater. The amount of renewable energy produced by PRO depends on the water flow from the WWTPs, and from the operating pressure of this section of the desalination hybrid process. Presently, the reduction of the SEC is between $12.7 \%$ and $24 \%$ compared to that of ISWRO. At the same time, the problem of discharging excessively concentrated brines into the sea is practically solved.

The ongoing research and technological development activities aim to improve the performance of the membranes through the homogenization of the density of the filtering surface and the reduction of polarization effects by modifying their hydrophobicity.

In the short-medium term, when better-performing membranes will likely be available for full-scale application, $\mathrm{PRO}$ could be operated with a pressure significantly higher than $\Delta \pi / 2$. In such a case, the reduction of the SEC would be close to $30 \%$, while the atmospheric pollution related to GHG emission would be further reduced as the $\mathrm{CO}_{2}$ produced would be lesser than now of about $0.6 \mathrm{~kg} / \mathrm{m}^{3}$ of FW.

The proposed strategy can be applied in all arid urban areas of the world to alleviate or eliminate the adverse environmental effects of seawater desalination as it is currently carried out. Nevertheless, what appears more important is the possibility of restarting a downward trend for the SEC and, presumably, for the unit cost of desalinated water, after years of stagnation. The latter can only be reliably estimated on a case-by-case basis through a rigorous economic analysis that considers the investments necessary for the interconnection of services and the RO-PRO hybridization.

Author Contributions: Conceptualization, G.D.G.; methodology, G.D.G. and G.T.; investigation, G.D.G., G.T. and P.R.; resources, G.D.G., G.T. and P.R.; writing-original draft preparation, G.T.; writing-review and editing, G.D.G., G.T. and P.R.; supervision, G.D.G.; visualization, P.R. All authors have read and agreed to the published version of the manuscript.

Funding: This research received no external funding.

Institutional Review Board Statement: Not applicable.

Informed Consent Statement: Not applicable.

Data Availability Statement: Not applicable.

Acknowledgments: The authors thank the administrative and technical staff of the department of Industrial and Information Engineering and of Economics of the University of L'Aquila for helpful support.

Conflicts of Interest: The authors declare no conflict of interest.

\section{References}

1. Eakins, B.W.; Sharman, G.F. Volumes of the World's Oceans from ETOPO1; NOAA National Geophysical Data Center: Boulder, CO, USA, 2010.

2. Bennett, A. 50th Anniversary: Desalination: 50 Years of Progress. Filtr. Sep. 2013, 50, 32-39. [CrossRef]

3. Yfantis, D.; Yfantis, A. Aristotle and seawater desalination: A new explanation of an experiment described in meteorologica and historia animalium. In The Capital of Knowledge; Society for the Propagation of Useful Books: Athens, Greece, 2020; pp. 167-173, ISBN 978-960-8351-83-7. 
4. Micale, G.; Cipollina, A.; Rizzuti, L. Seawater Desalination for Freshwater Production. In Seawater Desalination: Conventional and Renewable Energy Processes; Micale, G., Rizzuti, L., Cipollina, A., Eds.; Green Energy and Technology; Springer: Berlin/Heidelberg, Germany, 2009; pp. 1-15, ISBN 978-3-642-01150-4.

5. Altaee, A.; Millar, G.J.; Zaragoza, G. Integration and Optimization of Pressure Retarded Osmosis with Reverse Osmosis for Power Generation and High Efficiency Desalination. Energy 2016, 103, 110-118. [CrossRef]

6. Aende, A.; Gardy, J.; Hassanpour, A. Seawater desalination: A review of forward osmosis technique, its challenges, and future prospects. Processes 2020, 8, 901. [CrossRef]

7. Barba, D.; Liuzzo, G.; Tagliaferri, G. Multi Stage Flash-Evaporator. U.S. Patent No. 3,763,014, 2 October 1973.

8. Barba, D.; D'Agostino, C.; Liuzzo, G. Desalination of Sea or Brackish Water by Multi-Stage Flash Evaporation. U.S.Patent No. 3,684,661, 15 August 1972.

9. Bennett, A. Desalination Trends: What's the Future for Desalination? Filtr. Sep. 2012, 49, 12-15. [CrossRef]

10. Tomassi, G. Integration of Pressure Retarded Osmosis with Reverse Osmosis for Energy Recovery and High Efficiency Desalination of Sea Water. Bachelor's Thesis, University of L'aquila, L'Aquila AQ, Italy, 2021.

11. Bargiacchi, E.; Orciuolo, F.; Ferrari, L.; Desideri, U. Use of Pressure-Retarded-Osmosis to Reduce Reverse Osmosis Energy Consumption by Exploiting Hypersaline Flows. Energy 2020, 211, 118969. [CrossRef]

12. Elsaid, K.; Kamil, M.; Sayed, E.T.; Abdelkareem, M.A.; Wilberforce, T.; Olabi, A. Environmental Impact of Desalination Technologies: A Review. Sci. Total. Environ. 2020, 748, 141528. [CrossRef]

13. World Bank. The Role of Desalination in an Increasingly Water-Scarce World; Water Papers; World Bank: Washington, DC, USA, 2019.

14. Quanta Acqua c'è Nel Mondo. Available online: http://www.expo2015.org/magazine/it/sostenibilita/quanta-acqua-c-e-nelmondo.html (accessed on 20 June 2021).

15. Transforming Our World: The 2030 Agenda for Sustainable Development I Department of Economic and Social Affairs. Available online: https://sdgs.un.org/2030agenda (accessed on 22 June 2021).

16. Barba, D.; Brandani, V.; Di Giacomo, G.; Foscolo, P.U. Magnesium oxide production from concentrated brines. Desalination 1980, 33, 241-250. [CrossRef]

17. Kim, S.; Joo, H.; Moon, T.; Kim, S.H.; Yoon, J. Rapid and selective lithium recovery from desalination brine using an electrochemical system. Environ. Sci. Process. Impacts 2019, 21, 667-676. [CrossRef] [PubMed]

18. Lee, S.; Choi, J.; Park, Y.G.; Shon, H.; Ahn, C.H.; Kim, S.H. Hybrid desalination processes for beneficial use of reverse osmosis brine: Current status and future prospects. Desalination 2019, 454, 104-111. [CrossRef]

19. El-Hady, B.; Kashyout, A.; Hassan, A.; Hassan, G.; El-Banna Fath, H.; El-Wahab Kassem, A.; Elshimy, H.; Shaheed, M.H. Hybrid renewable energy/hybrid desalination potentials for remote areas: Selected cases studied in Egypt. RSC Adv. 2021, 11, 13201-13219. [CrossRef]

20. Esmaeilion, F. Hybrid renewable energy systems for desalination. Appl. Water Sci. 2020, 10, 1-47. [CrossRef]

21. Vanoppen, M.; Blandin, G.; Derese, S.; Le Clech, P.; Post, J.; Verliefde, A.R.D. Salinity gradient power and desalination. In Sustainable Energy from Salinity Gradients; Elsevier: Amsterdam, The Netherlands, 2016.

22. Makabe, R.; Ueyama, T.; Sakai, H.; Tanioka, A. Commercial pressure retarded osmosis systems for seawater desalination plants. Membranes 2021, 11, 69. [CrossRef] [PubMed]

23. Yip, N.Y.; Tiraferri, A.; Phillip, W.A.; Schiffman, J.D.; Elimelech, M. High performance thin-film composite forward osmosis membrane. Environ. Sci. Technol. 2010, 44, 3812-3818. [CrossRef]

24. Li, L.; Shi, W.; Yu, S. Research on forward osmosis membrane technology still needs improvement in water recovery and wastewater treatment. Water 2020, 12, 107. [CrossRef]

25. Morillo, J.; Usero, J.; Rosado, D.; El Bakouri, H.; Riaza, A.; Bernaola, F.J. Comparative study of brine management technologies for desalination plants. Desalination 2014, 336, 32-49. [CrossRef]

26. Ghaffour, N.; Missimer, T.M.; Amy, G.L. Technical Review and Evaluation of the Economics of Water Desalination: Current and Future Challenges for Better Water Supply Sustainability. Desalination 2013, 309, 197-207. [CrossRef]

27. Barba, D.; Di Giacomo, G.; Evangelista, F.; Tagliaferri, G. High temperature distillation process with sea water feed decalcification pretreatment. Desalination 1982, 40,347-355. [CrossRef]

28. Wang, J.; Tanuwidjaja, D.; Bhattacharjee, S.; Edalat, A.; Jassby, D.; Hoek, E.M.V. Produced water desalination via pervaporative distillation. Water 2020, 12, 3560. [CrossRef]

29. Wang, P.; Chung, T.S. A conceptual demonstration of freeze desalination-membrane distillation (FD-MD) hybrid desalination process utilizing liquefied natural gas (LNG) cold energy. Water Res. 2012, 46, 4037-4052. [CrossRef]

30. Feria-Díaz, J.J.; Correa-Mahecha, F.; López-Méndez, M.C.; Rodríguez-Miranda, J.P.; Barrera-Rojas, J. Recent desalination technologies by hybridization and integration with reverse osmosis: A review. Water 2021, 13, 1369. [CrossRef]

31. Bland, E. Study: Bacteria Can Make Salt Water Drinkable; NBC, 2009. Available online: https://www.nbcnews.com/id/wbna32558 231. (accessed on 11 June 2021).

32. Wang, Q.; Zhou, Z.; Li, J.; Tang, Q.; Hu, Y. Investigation of the Reduced Specific Energy Consumption of the RO-PRO Hybrid System Based on Temperature-Enhanced Pressure Retarded Osmosis. J. Membr. Sci. 2019, 581, 439-452. [CrossRef]

33. Tamburini, A.; Giacalone, F.; Cipollina, A.; Grisafi, F.; Vella, G.; Micale, G. Pressure retarded osmosis: A membrane process for environmental sustainability. Chem. Eng. Trans. 2016, 47, 355-360. [CrossRef] 
34. Qasim, M.; Badrelzaman, M.; Darwish, N.N.; Darwish, N.A.; Hilal, N. Reverse osmosis desalination: A state-of-the-art review. Desalination 2019, 459, 59-104. [CrossRef]

35. Darwish, M.A.; Abdel-Jawad, M.; Hauge, L.J. A new dual-function device for optimal energy recovery and pumping for all capacities of RO systems. Desalination 1989, 75, 25-39. [CrossRef]

36. Andrews, W.T.; Laker, D.S. A twelve-year history of large scale application of work-exchanger energy recovery technology. Desalination 2001, 138, 201-206. [CrossRef]

37. Chung, H.W.; Banchik, L.D.; Swaminathan, J.; Lienhard, V.J.H. On the Present and Future Economic Viability of Stand-Alone Pressure-Retarded Osmosis. Desalination 2017, 408, 133-144. [CrossRef]

38. Aumesquet-Carreto, M.; Ortega-Delgado, B.; Garcia-Rodriguez, L. Improving the Performance of Reverse Osmosis Desalination Process with Pressure Retarded Osmosis. EERES4WATER PROJECT (EAPA 1058/2018), European Regional Development Fund. Seville, ES. 2019. Available online: https:/ /www.eeres4water.eu/wp-content/uploads/2020/05/Report-Action-6.2-PRO-SWRO.pdf (accessed on 11 June 2021).

39. Evans, Graham. "Persian Gulf". Encyclopedia Britannica. Available online: https://www.britannica.com/place/Persian-Gulf (accessed on 11 June 2021).

40. Escobar, I.C.; Schäfer, A. Sustainable Water for the Future: Water Recycling Versus Desalination; Elsevier: Amsterdam, The Netherlands, 2009; ISBN 978-0-08-093217-0.

41. Barau, A.S.; Al Hosani, N. Prospects of Environmental Governance in Addressing Sustainability Challenges of Seawater Desalination Industry in the Arabian Gulf. Environ. Sci. Policy 2015, 50, 145-154. [CrossRef]

42. Lattemann, S. Protecting the Marine Environment. In Seawater Desalination: Conventional and Renewable Energy Processes; Micale, G., Rizzuti, L., Cipollina, A., Eds.; Green Energy and Technology; Springer: Berlin/Heidelberg, Germany, 2009; pp. 273-299, ISBN 978-3-642-01150-4.

43. Guirguis, M. Energy Recovery Devices in Seawater Reverse Osmosis Desalination Plants with Emphasis on Efficiency and Economical Analysis of Isobaric versus Centrifugal Devices; University of South Florida: Tampa, FL, USA, 2011.

44. Sawaki, N.; Chen, C.-L. Cost Evaluation for a Two-Staged Reverse Osmosis and Pressure Retarded Osmosis Desalination Process. Desalination 2021, 497, 114767. [CrossRef]

45. Di Giacomo, G.; Scimia, F.; Taglieri, L. Solvent Activity and Osmotic Pressure of Binary Aqueous and Alcoholic Solutions of Calcium Chloride up to $368 \mathrm{~K}$ and High Salt Concentration. Indian J. Chemistry-Sect. A (IJCA) 2020, 56, $297-304$.

46. Gekas, V.; Gonzalez, C.; Sereno, A.; Chiralt, A.; Fito, P. Mass Transfer Properties of Osmotic Solutions. I. Water Activity and Osmotic Pressure. Int. J. Food Prop. 1998, 1, 95-112. [CrossRef]

47. Nayar, K.G.; Sharqawy, M.H.; Banchik, L.D.; Lienhard, V.J.H. Thermophysical Properties of Seawater: A Review and New Correlations That Include Pressure Dependence. Desalination 2016, 390, 1-24. [CrossRef]

48. Sastry, S. Study of Parameters before and after Treatment of Municipal Waste Water from an Urban Town. Int. J. Appl. Environ. Sci. 2013, 3, 41-48.

49. Christodoulou, A.; Stamatelatou, K. Overview of Legislation on Sewage Sludge Management in Developed Countries Worldwide. Water Sci. Technol. 2015, 73, 453-462. [CrossRef] [PubMed]

50. Aragón-Briceño, C.I.; Grasham, O.; Ross, A.B.; Dupont, V.; Camargo-Valero, M.A. Hydrothermal Carbonization of Sewage Digestate at Wastewater Treatment Works: Influence of Solid Loading on Characteristics of Hydrochar, Process Water and Plant Energetics. Renew. Energy 2020, 157, 959-973. [CrossRef]

51. Hara, K.; Kuroda, M.; Yabar, H.; Kimura, M.; Uwasu, M. Historical Development of Wastewater and Sewage Sludge Treatment Technologies in Japan-An Analysis of Patent Data from the Past 50 Years. Environ. Dev. 2016, 19, 59-69. [CrossRef]

52. Djandja, O.S.; Wang, Z.-C.; Wang, F.; Xu, Y.-P.; Duan, P.-G. Pyrolysis of Municipal Sewage Sludge for Biofuel Production: A Review. Ind. Eng. Chem. Res. 2020, 59, 16939-16956. [CrossRef]

53. Hong, J.; Hong, J.; Otaki, M.; Jolliet, O. Environmental and Economic Life Cycle Assessment for Sewage Sludge Treatment Processes in Japan. Waste Manag. 2009, 29, 696-703. [CrossRef]

54. Jatav, H.S.; Singh, S.K.; Singh, Y.; Kumar, O. Biochar and Sewage Sludge Application Increases Yield and Micronutrient Uptake in Rice (Oryza Sativa L.). Commun. Soil Sci. Plant Anal. 2018, 49, 1617-1628. [CrossRef]

55. Onaka, T. Sewage Can Make Portland Cement: A New Technology for Ultimate Reuse of Sewage Sludge. Water Sci. Technol. 2000, 41, 93-98. [CrossRef]

56. Werther, J.; Ogada, T. Sewage Sludge Combustion. Prog. Energy Combust. Sci. 1999, 25, 55-116. [CrossRef]

57. Kim, J.; Park, K.; Yang, D.R.; Hong, S. A Comprehensive Review of Energy Consumption of Seawater Reverse Osmosis Desalination Plants. Appl. Energy 2019, 254, 113652. [CrossRef]

58. Al-Hazmi, A.A. IDA Global Connections-Fall 2019. Available online: https://issuu.com/idadesal/docs/ida_fall19_digital (accessed on 22 June 2021).

59. Tawalbeh, M.; Al-Othman, A.; Abdelwahab, N.; Alami, A.H.; Olabi, A.G. Recent Developments in Pressure Retarded Osmosis for Desalination and Power Generation. Renew. Sustain. Energy Rev. 2021, 138, 110492. [CrossRef]

60. Touati, K.; Tadeo, F.; Kim, J.H.; Silva, O.A.A.; Chae, S.H. Pressure Retarded Osmosis: Renewable Energy Generation and Recovery; Academic Press: Cambridge, MA, USA, 2017; ISBN 978-0-12-812315-7.

61. Pattle, R.E. Production of Electric Power by Mixing Fresh and Salt Water in the Hydroelectric Pile. Nature 1954, 174, 660. [CrossRef] 
62. Sarp, S.; Li, Z.; Saththasivam, J. Pressure Retarded Osmosis (PRO): Past Experiences, Current Developments, and Future Prospects. Desalination 2016, 389, 2-14. [CrossRef]

63. Prante, J.L.; Ruskowitz, J.A.; Childress, A.E.; Achilli, A. RO-PRO Desalination: An Integrated Low-Energy Approach to Seawater Desalination. Appl. Energy 2014, 120, 104-114. [CrossRef] 